\title{
The mRNA Expression Profile of PD-1 and PD-L1 in Peripheral Blood of Colorectal Cancer Patients
}

\author{
Ajoedi ${ }^{1}$, Muhammad Al Azhar ${ }^{2}$, Siti Nadliroh ${ }^{2}$, Sri Hartini ${ }^{3}$, Rizka Andalusia ${ }^{2}$, Arief Budi \\ Witarto $^{4}$ \\ ${ }^{1}$ Digestive Surgery Department, National Cancer Center-Dharmais Cancer Hospital, Jakarta, Indonesia \\ ${ }^{2}$ Research and Development Department, National Cancer Center-Dharmais Cancer Hospital, Jakarta, Indonesia \\ ${ }^{3}$ Clinical Pathology Department, National Cancer Center-Dharmais Cancer Hospital, Jakarta, Indonesia \\ ${ }^{4}$ Faculty of Biotechnology, Sumbawa University of Technology, West Nusa Tenggara, Indonesia
}

\section{ARTICLE INFO}

Received : 31 July 2019

Reviewed : 01 August 2019

Accepted : 27 September 2019

\section{Keywords:}

colorectal cancer, immunotherapy, PD-1, PD-L1
*Corresponding author:

Ajoedi

Digestive Surgery Department,

National Cancer Center-Dharmais

Cancer Hospital, Jakarta, Indonesia.

ajoedi_rskddharmais@yahoo.com

\begin{abstract}
A B STRACT
Background: Immunotherapy using immune checkpoint inhibitors has currently emerged as an effective treatment for a subset of colorectal cancer (CRC) patients. The roles of PD-1 and PD-L1 expression levels in peripheral blood to predict patient's response to immune checkpoint inhibitors are not well established. Therefore, we analyzed PD-1 and PD-L1 mRNA expression levels of peripheral blood in Indonesian CRC patients and explored the association with the clinicopathological features.
\end{abstract}

Methods: Peripheral blood of 25 CRC patients and 10 healthy individuals were collected in Dharmais Hospital-National Cancer Center from 2017 to 2018. PD-1 and PD-L1 mRNA expression levels were analyzed using real time PCR. The associations with clinicopathological variables were analyzed with fisher-exact test or chi square test.

Results: PD-1 mRNA expression levels were significantly lower in CRC patients compared to healthy individuals $(\mathrm{HI})$ (mean: $0.0015 \pm 0.0013$ and $0.017 \pm 0.010$ respectively, $\mathrm{p}<0.001$ ). Although PD-L1 mRNA expression levels were lower in CRC patients, the difference was not statistically significant (mean in CRC and $\mathrm{HI}: 0.021 \pm 0.013$ and $0.034 \pm 0.028$ respectively, $\mathrm{p}=0.125$ ). The expression of PD-L1 was higher in CRC females compared to males $(p=0.030)$. The expression levels of PD-L1 were not associated with different ages $(p=0.673)$, stages $(p=0.372)$, histological type of colorectal cancer $(p=0.852)$, patient status $(p=1.000)$, and body mass index $(p=0.514)$.

Conclusions: The mRNA expression levels of PD-1 and PD-L1 were lower in CRC patients compared to healthy controls. Expression of PD-L1 were correlated with sex, but not correlated with ages, stages, histological type of CRC, patient status, and body mass index.

\section{INTRODUCTION}

Colorectal cancer (CRC) is the number 2 cancer type that causes death. In 2018, there were 1.8 million deaths worldwide caused by colorectal cancer [1]. Several treatment types which are commonly used to treat cancer are surgery, chemotherapy and radiotherapy [2]. However, the recurrence rate and adverse effect using these treatments is still high in colorectal cancer patients [3]. Thus, alternative therapy should be developed. Immunotherapy has emerged as a promising therapeutic strategy against cancer. One of the most popular immunotherapeutic approaches for treating cancer patients is blocking immune checkpoint pathways [4].

Immune checkpoint normally functions to control the balance of immune system. The most studied immune checkpoint molecules are Programmed cell death-1 (PD-1) and programmed cell death ligand-1 (PDL1) [4]. PD-1 is a protein receptor commonly expressed by T-cell, B-cell, monocyte, dendritic cell, NK cell, regulatory $T$ cell, and tumor infiltrating lymphocytes (TILs) [5,6]. PD-L1 is the ligand of PD-1 and usually expressed by macrophages, dendritic cells, resting $T$ cells, pancreatic islet cells, B cells, vascular endothelial cells and various types of cancer [7]. The interaction between PD-L1 and PD-1 reduces $T$ cell activity and increases $\mathrm{T}$ cell apoptosis, so that it promotes tumor growth $[4,8]$.

Inhibiting the interaction between PD-L1 and PD-1 molecules with monoclonal antibodies may mediate antitumor activity and enhance T-cell responses, thus promote tumor regression and inhibit tumor growth 
$[8,9]$. Several inhibitors that target PD-1 or PD-L1 (anti PD-1/ anti PD-L1) have been approved by FDA and show good efficacy against several cancer types. Studies have shown that anti PD-1/ anti PD-L1 can improve clinical outcomes in various types of cancers including colorectal cancer $[4,8]$.

Measurement of PD-L1 expression in cancer tissues using immunohistochemistry assay has been used to predict patient response to therapy with immune checkpoint inhibitor and its expression is also correlated with prognosis in several cancer types such as malignant melanoma, lung cancer (NSCLC), thymoma, bladder, renal cell carcinomas $(R C C)$, and ovarian cancer $[10,11]$. However, previous studies indicated that PD-1 and PDL1 expression in peripheral blood potentially can be used to predict cancer progression and identify the types of patients who respond anti PD-1/ PD-L1 therapy [12-15]. The use of blood is easier and may have clinical benefit for monitoring sequential tumor response to immunotherapy [12].

However, not many studies have been done analyzing mRNA expression of PD-1 and PD-L1 in peripheral blood of CRC patients. The predictive value of PD-1 and PD$\mathrm{L} 1$ expression is also remain controversial in CRC patients, with some studies on PD-L1 reporting conflicting results $[16,17]$. Besides, research of PD-1/ PD-L1 is also very rare in Indonesia. Thus, this study aims to profile PD-1 and PD-L1 mRNA expression in peripheral blood of colorectal cancer patients in Dharmais HospitalNational Cancer Center Indonesia using quantitative real-time PCR assay. The association between PD-1/ PD-L1 expression and clinicopathological features in colorectal cancer patients is also discussed.

\section{METHODS}

\section{Patients}

The sample used in this study was the peripheral blood of 25 colorectal cancer patients collected in Dharmais Hospital-National Cancer Center from 2017 to 2018 and 10 healthy individuals as controls. Minimum $1 \mathrm{~mL}$ of blood samples were collected using EDTA tube.

This study has been approved by Ethical Committee of Dharmais Cancer Hospital with ethical approval number 085/KEPK/X/2017 for colorectal cancer patients and $075 / K E P K / V / 2018$ for healthy individuals. The informed consents of patients were also obtained. The patient inclusion criteria include positive colorectal cancer patients with anatomical pathology confirmation, not receiving any therapy yet, and above 18 years old.

\section{RNA extraction and CDNA synthesis}

The extraction of total RNA was done using Total RNA Mini Kit for Blood/Culture Cell (GeneAid) following
DNase treatment using RNase-Free DNase set (Geneaid). The purity and concentration of mRNA was measured using Nanodrop spectrophotometer (Thermo Scientific). All total RNA samples were reverse-transcribed using SensiFAST cDNA Synthesis Kit (Geneaid) to generate cDNA. The amount of RNA samples which reverse-transcribed was made equal $(50 \mathrm{ng})$. All the procedures were conducted according to the manufacturer's instruction.

\section{Primer and probes}

Primers and probe used in this study were newly designed to span exon-exon junction to avoid genomic DNA amplification. The sequence of PD-1, PD-L1, and GAPDH primers and probes used in this study can be seen in Table 1. Each primer pair and probe was mixed and formulated into Custom TaqMan Gene Expression Assay (Applied Biosystem).

Table 1. Primers and probes used in real-time PCR

\begin{tabular}{ll}
\hline Primer & Sequence \\
\hline PD-1 for & 5'-ccaaggcgcagatcaaagaga-3' \\
PD-1 rev & 5'-tgggctgtgggcactt-3' \\
PD-1 probe & 5'-tctgggcggtgctacaact-3' \\
PD-L1 for & 5'-tgtgaaagtcaatgcccat-3' \\
PD-L1 rev & 5'-tgtcagttcatgttcagaggt-3' \\
PD-L1 probe & 5'-attttggttgtggatccagtc-3' \\
GAPDH for & 5'-agcctcaagatcatcagcaa-3' \\
GAPDH rev & 5'-actgtggtcatgagtccttc-3' \\
GAPDH probe & 5'-ctgcaccaccaactgcttag-3' \\
\hline
\end{tabular}

\section{Real-time quantitative PCR}

Real-time quantitative PCR was conducted using 7500 Fast Real-Time PCR system (Applied Biosystem). Each sample was duplicated. The reaction mixture contained 100 ng of cDNA, custom TaqMan gene expression assay (Applied Biosystem), TaqMan gene expression master mix (Applied Biosystem), and nuclease free water (Ambion). The temperature set was as follows: hold stage at $50^{\circ} \mathrm{C}$ for 2 minutes and $95^{\circ} \mathrm{C}$ for 10 minutes, followed by 40 cycles of denaturation at $95^{\circ} \mathrm{C}$ for 15 second, and annealing and extension at $62^{\circ} \mathrm{C}$ for 1 minute. qPCR data was analyzed using livak method (18). The cycle threshold (CT) values of PD-1 and PD-L1 were normalized with $\mathrm{CT}$ value of GAPDH. To determine the high or low expression levels of PD-1 and PD-L1 in each CRC patient, the $\triangle C T$ value of each sample was compared with the average $\Delta \mathrm{CT}$ value of healthy individuals. The average PD-L1 $\triangle C T$ value of healthy individuals was 5.18. PD-L1 $\Delta C T$ values of samples below 5.18 were considered as high expression, while PD-L1 $\triangle \mathrm{CT}$ values above 5.18 were considered as low expression. 


\section{Statistical Analysis}

The data was analyzed using IBM SPSS Statistics 22 statistical software. Association between gene expression and clinicopathological features was analyzed using fisher-exact test or chi-square test. Comparison of mRNA expression between CRC patients and healthy individuals was analyzed using Mann-Whitney test and it is considered statistically significant if $p$-value is $<0.05$.

\section{RESULTS}

\section{Clinicopathological features of CRC patients and healthy individuals}

A total of 25 CRC patients and 10 healthy individuals as the control group were used in this study. Demographical characteristics of all participants and clinicopathological features of CRC patients are listed in Table 1. CRC patients consisted of 13 males and 12 females with the mean age of $53.7 \pm 13.7$. Healthy individuals included 5 males and 5 females with the mean age of $32.4 \pm 11.7$.

Table 2. Clinicopathological characteristic of samples used in this study

\begin{tabular}{|c|c|c|}
\hline & CRC patients & $\begin{array}{l}\text { Healthy } \\
\text { individuals }\end{array}$ \\
\hline & n (\%) & n (\%) \\
\hline Number of cases & 25 & 10 \\
\hline \multicolumn{3}{|l|}{ Sex } \\
\hline Male & $13(52 \%)$ & $5(50 \%)$ \\
\hline Female & $12(48 \%)$ & $5(50 \%)$ \\
\hline Age $(M \pm S D)$ & $53.7 \pm 13.7$ & $32.4 \pm 11.7$ \\
\hline Age range & $28-77$ & $19-50$ \\
\hline \multicolumn{3}{|l|}{ Cancer stage } \\
\hline II & $6(24 \%)$ & \\
\hline III & $13(52 \%)$ & \\
\hline IV & $6(24 \%)$ & \\
\hline \multicolumn{3}{|l|}{ Type of colorectal cancer } \\
\hline Colon cancer & $8(32 \%)$ & \\
\hline Rectal cancer & $10(40 \%)$ & \\
\hline Sigmoid cancer & $2(8 \%)$ & \\
\hline Colon sigmoid cancer & $2(8 \%)$ & \\
\hline Rectal sigmoid cancer & $3(12 \%)$ & \\
\hline \multicolumn{3}{|l|}{ Patient status } \\
\hline Life & 22 (88\%) & \\
\hline Dead & $3(12 \%)$ & \\
\hline \multicolumn{3}{|l|}{ Body Mass Index } \\
\hline Normal & $19(76 \%)$ & \\
\hline Underweight & $3(12 \%)$ & \\
\hline Overweight & $3(12 \%)$ & \\
\hline
\end{tabular}

M: Mean, SD: Standard Deviation
Comparison of PD-1 and PD-L1 expression in blood between CRC patients and healthy individuals

The results of PD-1 and PD-L1 mRNA expression analyses showed that PD-1 and PD-L1 expression is lower in colorectal cancer patients compared to healthy individuals (Figure 1). The difference of PD-1 mRNA expression was statistically significant (mean expression levels of PD-1 in CRC patients and healthy individuals were $0.0015 \pm 0.0013$ and $0.017 \pm 0.010$ respectively, $\mathrm{p}<0.001$ ), while the PD-L1 mRNA expression was not statistically significant (mean expression levels of PD-L1 in CRC patients and healthy individuals were $0.021 \pm$ 0.013 and $0.034 \pm 0.028$, respectively, $p=0.125$ ).
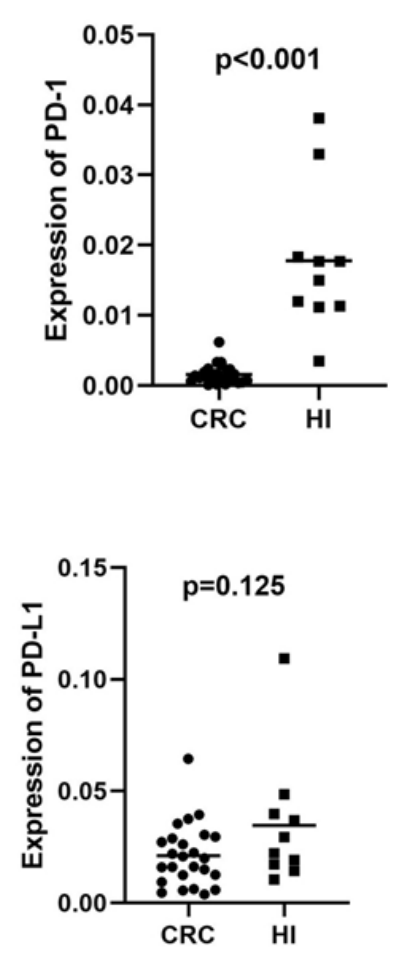

Figure 1. mRNA expression of PD-1 and PD-L1 of colorectal cancer patients (CRC) and healthy individuals (HI). The expression was calculated using $2^{-\Delta C T}$ calculation method. The lines in the centre of each group represent means.

\section{Expression of PD-1 and PD-L1 and clinicopathological features of patients}

The results showed that $7 / 25$ patients (28\%) have higher PD-L1 expression, whereas all CRC patients have lower PD-1 expression. The correlation of PD-L1 expression and clinicopathological features is shown in Table 3. PDL1 expression is associated with sex $(p=0.030)$ where females tend to express more of higher PD-L1 expression. There was no significant correlation between PD-L1 expression and age, stage, CRC type, patient status, and body mass index. PD-1 expression cannot be associated with clinicopathological features because its expression in all CRC patients is low. 
Table 3. Correlation between clinicopathological features and PD-L1 mRNA expressions in colorectal cancer patients

\begin{tabular}{|c|c|c|c|c|}
\hline Parameter & $\begin{array}{c}\text { Low expression } \\
\mathrm{n}(\%)\end{array}$ & $\begin{array}{c}\text { High expression } \\
\mathrm{n}(\%)\end{array}$ & $\begin{array}{c}\text { Odds Ratio } \\
\text { (95\% Cl) }\end{array}$ & p-value \\
\hline \multicolumn{5}{|l|}{ Age } \\
\hline$\leq 50$ & $6(33.3)$ & $3(42.9)$ & \multirow{2}{*}{$\begin{array}{c}0.67 \\
(0.11-3.99) \\
\end{array}$} & \multirow{2}{*}{0.673} \\
\hline$>50$ & $12(66.7)$ & $4(57.1)$ & & \\
\hline \multicolumn{5}{|l|}{ Sex } \\
\hline Male & $12(66.7)$ & $1(14.3)$ & \multirow{2}{*}{$\begin{array}{c}12 \\
(1.16-123.68)\end{array}$} & \multirow{2}{*}{0.030} \\
\hline Female & $6(33.3)$ & $6(85.7)$ & & \\
\hline \multicolumn{5}{|l|}{ Stage } \\
\hline II & $3(16.7)$ & $3(42.9)$ & \multirow{3}{*}{$\begin{array}{c}0.26 \\
(0.04-1.86)\end{array}$} & \multirow{3}{*}{0.372} \\
\hline III & $10(55.5)$ & $3(42.9)$ & & \\
\hline IV & $5(27.8)$ & $1(14.3)$ & & \\
\hline \multicolumn{5}{|l|}{ Histological Type } \\
\hline Colon cancer & $6(33.3)$ & $2(28.6)$ & \multirow{5}{*}{$\begin{array}{c}1.01 \\
(0.52-1.95)\end{array}$} & \multirow{5}{*}{0.852} \\
\hline Rectal cancer & 7 (38.8) & $3(42.9)$ & & \\
\hline Sigmoid cancer & $1(5.5)$ & $1(14.3)$ & & \\
\hline Colon sigmoid cancer & $2(11.1)$ & 0 & & \\
\hline Rectal sigmoid cancer & $2(11.1)$ & $1(14.3)$ & & \\
\hline \multicolumn{5}{|l|}{ Patient Status } \\
\hline Life & $16(88.9)$ & $6(85.7)$ & \multirow{2}{*}{$\begin{array}{c}1.33 \\
(0.10-17.54)\end{array}$} & \multirow{2}{*}{1.000} \\
\hline Dead & $2(11.1)$ & $1(14.3)$ & & \\
\hline \multicolumn{5}{|l|}{ Body Mass Index } \\
\hline Normal & $13(72.2)$ & $6(85.7)$ & \multirow{3}{*}{$\begin{array}{c}0.79 \\
(0.20-3.09)\end{array}$} & \multirow{3}{*}{0.514} \\
\hline Underweight & $3(16.7)$ & 0 & & \\
\hline Overweight & 2 (11.1) & $1(14.3)$ & & \\
\hline
\end{tabular}

$\mathrm{Cl}$ : Confidence Interval

\section{DISCUSSION}

The result showed that PD-1 mRNA expression decreased in peripheral blood of CRC patients compared to healthy individuals. Previous studies have shown that PD-1 expression tends to be low in CRC with advanced stages [19]. Meanwhile, most samples used in this study were also CRC patients with advanced stages (76\%), thus this study supports the result from Gasser et al. [19].

This study also revealed that PD-L1 mRNA expression in blood seems to be low in colorectal cancer patients compared to healthy individuals, but the difference is not statistically significant $(p=0.125)$. The results showed that $28 \%(7 / 25)$ of CRC patients have high PD-L1 mRNA expression. Previous related studies which analyzed PDL1 expression also showed that positive PD-L1 expression in colorectal cancer was only found in small number of samples. These studies reported that the rates of positive PD-L1 expression are only 5\% (19/394) [20], $14 \%(15 / 107)$ [21], and 9\% [22] in CRC patients. It also has been shown that PD-L1 expression in colorectal cancers is significantly lower compared with other cancer types [21].
Our result showed that the mRNA expression levels of PD-1 and PD-L1 are lower in peripheral blood of CRC patients compared to healthy individuals. This might be caused by several factors such as reduced $T$ cell immunosuppression, enhanced $\mathrm{PD}-1^{+} \mathrm{CD} 4^{+} \mathrm{T}$ cell apoptosis, and PD-L1 gene methylation. The study by Zhong et al. [23] showed that lower PD-1 and PD-L1 mRNA expression in peripheral blood might be the indication of reduced $\mathrm{T}$ cell immunosuppression which may lead to the activation of abnormal T cell. The study by Hassan et al. [24] suggested that low PD-1 expression might be caused by enhanced apoptosis in PD- $1^{+} \mathrm{CD} 4^{+}$ T cell compartment. Another study by Goltz et al. [25] revealed that PD-L1 expression may be regulated by promoter methylation on PD-L1 gene in CRC. The study showed that PD-L1 methylation is inversely associated with PD-L1 mRNA expression. This indicates that low PD-L1 mRNA expression in CRC may be caused by methylation in PD-L1 gene. However, further studies to confirm these possibilities are needed.

This study also showed no significant correlation between the PD-L1 expression level in blood of CRC patients and age, stage, CRC type, patient status, and 
body mass index. Nevertheless, PD-L1 expression is correlated with sex where females tend to express more PD-L1 compared to males. The same finding was also found in the previous study by Rosenbaum et al. [22]. However, due to large range of confidence interval in sex parameter (Table 2), this finding still needs to be clarified by further studies with larger samples.

The previous study by Bae et al. [26] reported that low PD-L1 expression was significantly correlated with poor prognosis and tumor relapse in stage III CRC. In this study, we found that $76.9 \%$ CRC patients with stages III have low PD-L1 expression. This indicates that low PD-L1 expression may commonly be found in CRC with advanced stages, especially in stage III, and its low expression may be correlated with poor prognosis. However, the limitation of this study is the sample size which is too small. To find significant correlation between PD-1 and PD-L1 expression and clinicopathological features, the number of samples need to be added.

To the best of our knowledge, this is the first study analyzing PD-1 and PD-L1 mRNA expression in peripheral blood of CRC patients especially in Indonesia. This study could be an important contribution to predict a subset of CRC patients that will take benefits of immune checkpoint inhibitors. However, for future studies, the result needs to be compared with immunohistochemistry of PD-L1, a standardized method that has been used to predict the response of therapy with immune checkpoint inhibitor [27]. These findings also need further evaluation with a larger cohort of samples to further analyze the correlation between PD-1/PD-L1 and clinicopathological features and survival rate of CRC patients.

\section{CONCLUSIONS}

The mRNA expression of PD-1 and PD-L1 is lower in CRC patients compared to healthy individuals. Only $28 \%$ of CRC patients have high PD-L1 expression. Lower PD-1 and PD-L1 mRNA expression in CRC patients might be due to several factors such as reduced T-cell immunosuppression, enhanced $\mathrm{PD}-1^{+} \mathrm{CD} 4^{+} \mathrm{T}$ cell apoptosis, and methylation in PD-L1 gene. However, further studies in larger samples are needed to confirm the results.

\section{DECLARATIONS}

\section{Competing of Interest}

There is no conflict of interest in this study.

\section{Acknowledgement}

The authors wish to thank to Anita Meisita, S.KM for helping in analyzing the data and Department of Research and Development, Dharmais Hospital-National Cancer Center for providing the funding and instrument used in the study.

\section{REFERENCES}

1. International Agency of Research on Cancer (IARC). Latest global cancer data: Cancer burden rises to 18.1 million new cases and 9.6 million cancer deaths in 2018 [Internet]. Geneva: IARC; 12 Sep 2018 [cited 2019 April 15]. Available from: https://www.who. int/cancer/PRGlobocanFinal.pdf

2. DeSantis CE, Lin CC, Mariotto AB, Siegel RL, Stein KD, Kramer JL, et al. Cancer treatment and survivorship statistics, 2014. CA Cancer J Clin. 2014;64(4): 252-71.

3. Augestad KM, Merok MA, Ignatovic D. Tailored treatment of colorectal cancer: Surgical, molecular, and genetic considerations. Clin Med Insights Oncol. 2017;11.

4. Topalian SL, Taube JM, Anders RA, Pardoll DM. in cancer therapy. Nat Publ Gr. 2016;16(5): 275-87.

5. Keir ME, Butte MJ, Freeman GJ, Sharpe AH. PD-1 and Its Ligands in Tolerance and Immunity. Annu Rev Immunol. 2008;26(1): 677-704.

6. Francisco LM, Salinas VH, Brown KE, Vanguri VK, Freeman GJ, Kuchroo VK, et al. PD-L1 regulates the development, maintenance, and function of induced regulatory T cells. J Exp Med. 2009;206(13): 3015-29.

7. He J, Hu Y, Hu M, Li B. Development of PD-1 / PDL1 Pathway in Tumor Immune Microenvironment and Treatment for Non-Small Cell Lung Cancer. Nat Publ Gr. 2015;(July): 1-9.

8. Pardoll DM. The blockade of immune checkpoints in cancer immunotherapy. Nat Publ Gr [Internet]. 2012;12(4): 252-64. Available from: http://dx.doi. org/10.1038/nrc3239

9. Valentini AM, Pinto F Di, Cariola F, Guerra V, Caruso ML, Pirrelli M. PD-L1 expression in colorectal cancer defines three subsets of tumor immune microenvironments. 2018;9(9): 8584-96.

10. Hino R, Kabashima K, Kato Y, Yagi H, Nakamura M, Honjo $\mathrm{T}$, et al. Tumor cell expression of programmed cell death-1 ligand 1 is a prognostic factor for malignant melanoma. Cancer. 2010;116(7): 1757-66.

11. Wu P, Wu D, Li L, Chai Y, Huang J. PD-L1 and survival in solid tumors: A meta-analysis. PLoS One. 2015;10(6): 1-15.

12. Amatatsu $M$, Arigami $T$, Uenosono $Y$, Yanagita $S$, Uchikado $Y$, Kijima $Y$, et al. Programmed death-ligand 1 is a promising blood marker for predicting tumor 
progression and prognosis in patients with gastric cancer. Cancer Sci. 2018;109(3): 814-20.

13. Wang W, Shen G, Wu S, Song S, Ni Y, Suo Z, et al. PD-1 mRNA expression in peripheral blood cells and its modulation characteristics in cancer patients. Oncotarget. 2017;8(31): 50782-91.

14. MacFarlane AW, Jillab M, Plimack ER, Hudes GR, Uzzo RG, Litwin S, et al. PD-1 Expression on Peripheral Blood Cells Increases with Stage in Renal Cell Carcinoma Patients and Is Rapidly Reduced after Surgical Tumor Resection. Cancer Immunol Res. 2013;2(4): 320-31.

15. Waki K, Yamada T, Yoshiyama K, Terazaki Y, Sakamoto $S$, Matsueda S, et al. PD-1 expression on peripheral blood T-cell subsets correlates with prognosis in nonsmall cell lung cancer. Cancer Sci. 2014;105(10): 1229-35.

16. Song M, Chen D, Lu B, Wang C, Zhang J, Huang L, et al. PTEN Loss Increases PD-L1 Protein Expression and Affects the Correlation between PD-L1 Expression and Clinical Parameters in Colorectal Cancer. PLoS One. 2013;8(6).

17. Droeser RA, Hirt C, Viehl CT, Frey DM, Nebiker C, Huber $X$, et al. Clinical impact of programmed cell death ligand 1 expression in colorectal cancer. Eur J Cancer. 2013;49(9): 2233-42.

18. Livak KJ, Schmittgen TD. Analysis of relative gene expression data using real-time quantitative PCR and the 2- $\Delta \Delta C T$ method. Methods. 2001;25(4): 402-8.

19. Gasser M, Grimm M, Nichiporuk E, Bueter M, Lutz J, Lebedeva T, et al. PD-1/PD-L1 expression in colorectal cancer and its implications for apoptosis and tumor immune evasion. Cancer Res. 2006;66(8 Supplement): 1118 LP - 1118.

20. Lee LH, Cavalcanti MS, Segal NH, Hechtman JF, Martin R. Patterns and prognostic relevance of PD-1 and PD-L1 expression in colorectal carcinoma. Mod Pathol. 2016;29(11): 1433-42.
21. Albitar M, Sudarsanam S, Ma W, Jiang S, Chen W, Funari VA, et al. Expression of PD-L1 in colorectal cancer that lack mutations in RAS or TP53 genes. J Clin Oncol. 2017;35(15_suppl): e14500-e14500.

22. Rosenbaum MW, Bledsoe JR, Morales-oyarvide V, Huynh TG, Mino-kenudson M. PD-L1 expression in colorectal cancer is associated with microsatellite instability, BRAF mutation, medullary morphology and cytotoxic tumor-infiltrating lymphocytes. Mod Pathol. 2016: 1-9.

23. Zhong J, Chen S, Xu L, Lai J, Liao Z, Zhang T, et al. Lower expression of PD-1 and PD-L1 in peripheral blood from patients with chronic ITP Lower expression of PD-1 and PD-L1 in peripheral blood from patients with chronic ITP. Hematology. 2016: 8454.

24. Hassan SS, Akram M, King EC, Dockrell HM, Cliff JM. PD-1, PD-L1 and PD-L2 Gene Expression on T- Cells and Natural Killer Cells Declines in Conjunction with a Reduction in PD-1 Protein during the Intensive Phase of Tuberculosis Treatment. PLoS One. 2015: 1-15.

25. Goltz D, Gevensleben H, Dietrich J, Dietrich D. Pd-I1 (CD274) promoter methylation predicts survival in colorectal cancer patients. Oncoimmunology. 2017;6(1): 1-4.

26. Bae SU, Jeong WK, Baek SK, Kim NK, Hwang I. Prognostic impact of programmed cell death ligand 1 expression on long-term oncologic outcomes in colorectal cancer. Oncol Lett. 2018;16(4): 5214-22.

27. Koppel C, Schwellenbach H, Zielinski D, Eckstein S, Martin-Ortega M, D'Arrigo C, et al. Optimization and validation of PD-L1 immunohistochemistry staining protocols using the antibody clone 28-8 on different staining platforms. Mod Pathol. 2018;31(11): 1630-44. 